\title{
Sikap Dan Perilaku, Kinerja Produk, Kepuasan Dan Loyalitas Konsumen Kopi Bubuk (Studi Kasus Pada Usaha Kopi Bubuk Rantau Di Kecamatan Argamakmur Kabupaten Bengkulu Utara)
}

\author{
M. Ilwanda Sandy ${ }^{1}$, Satria Putra Utama ${ }^{2}$, Reswita ${ }^{3}$ \\ ${ }^{123}$ Fakultas Pertanian Universitas Bengkulu \\ ${ }^{3}$ reswita17@yahoo.co.id
}

\begin{abstract}
The purpose of this study was to analyze consumer attitudes and behavior, level of product importance and performance, satisfaction, and consumer loyalty to RANTAU ground coffee in Argamakmur District, North Bengkulu Regency, Bengkulu Province. The place where the research was carried out was in the RANTAU ground coffee business in ArgaMakmur District, North Bengkulu Regency, Bengkulu Province. In this study the data consists of secondary data and primary data. Primary data is taken by direct observation of the production process, interviews with customers of Rantau ground coffee, based on a list of questions or questionnaires that have been prepared. The secondary data in this study consisted of an overview of the RANTAU ground coffee business obtained directly from the RANTAU ground coffee business actor, books related to consumer behavior, satisfaction, and loyalty, previous research journals that have been published, both online and online. not online related to research. The research sample, namely consumers of RANTAU ground coffee, was taken by accidental sampling. The data analysis method used quantitative analysis method, Importance Performance Analysis (IPA) method, the Customer Satisfaction Index (CSI) method, and to analyze the level of consumer loyalty using the Loyalty Pyramid. The results of the study are consumer attitudes and behavior in making decisions to consume RANTAU ground coffee for reasons of good taste with an average frequency of consuming the product 3 times a day, the number of last purchases an average of 0.25 kilos. Consumers are satisfied with the product and intend to return to consume the product. If the product is not available at the location of purchase, consumers will go elsewhere to buy RANTAU ground coffee products. The measurement of product attribute performance with IPA from RANTAU coffee powder products, must be improved or improved, the attribute performance is the expiration date that has not been listed on the product. On average, consumers are satisfied with the RANTAU ground coffee business. Consumer satisfaction of RANTAU ground coffee is $66 \%$ which shows that consumers are satisfied overall. RANTAU ground coffee consumers are already in the loyal category because the value of consumers who are disloyal / like to switch coffee brands or switcher buyers (34\%) is smaller than the value of consumers who are loyal to buying Rantau ground coffee or Committed buyers (66\%).
\end{abstract}

Keywords: Satisfaction; Loyalty; Ground Coffee

\begin{abstract}
Abstrak
Tujuan penelitian ini adalah untuk menganalisis bagaimana sikap dan perilaku konsumen, tingkat kepentingan dan kinerja produk, kepuasan, dan loyalitas konsumen terhadap kopi bubuk RANTAU di Kecamatan Argamakmur Kabupaten Bengkulu Utara Provinsi Bengkulu. Tempat dilakukannya penelitian yaitu di usaha kopi bubuk RANTAU yang berada di Kecamatan ArgaMakmur Kabupaten Bengkulu Utara Propinsi Bengkulu.
\end{abstract}


Dalam penelitian ini data terdiri dari data sekunder dan data primer. Data primer diambil dengan cara mengamati langsung proses produksi, wawancara dengan pelanggan kopi bubuk Rantau, dengan berpedoman pada daftar pertanyaan atau kuesioner yang telah disusun. Data sekunder dalam penelitian ini terdiri dari gambaran umum usaha kopi bubuk RANTAU yang diperoleh langsung dari pelaku usaha kopi bubuk RANTAU, buku-buku yang berkaitan dengan perilaku, kepuasan, dan loyalitas konsumen, jurnal-jurnal penelitian terdahulu yang telah dipublikasi, baik secara online maupun tidak online yang berkaitan dengan penelitian. Sampel penelitian yaitu konsumen kopi bubuk RANTAU diambil secara Accidental sampling. Metode analisis data menggunakan Desktiptif Analisiys Methode kuantitave, Metode Importance Performance Analysis (IPA), Metode Indeks Kepuasan Konsumen atau Customer Satisfaction Index (CSI), dan untuk Menganalisis Tingkat Loyalitas Konsumen Menggunakan Piramida Loyalitas. Hasil dari penelitian adalah sikap dan perilaku konsumen dalam pengambilan keputusan mengkonsumsi kopi bubuk RANTAU karena alasan rasa yang enak dengan frekuensi mengkonsumsi produk rata-rata 3 kali sehari, jumlah pembelian terakhir rata-rata 0,25 kilo. Konsumen sudah merasakan puas terhadap produk dan berniat untuk kembali mengkonsumsi produk. Jika produk tidak tersedia dilokasi pembelian konsumen akan pergi ke tempat lain untuk membeli produk kopi bubuk RANTAU. Pengukuran kinerja atribut produk dengan IPA dari produk kopi bubuk RANTAU, harus ditingkatkan atau diperbaiki kinerja atributnya adalah tanggal kadaluarsa yang belum tercantum pada produk. Rata-rata konsumen puas terhadap usaha kopi bubuk RANTAU. Kepuasan konsumen kopi bubuk RANTAU yaitu sebesar 66\% yang menunjukkan secara keseluruhan konsumen sudah merasa puas. Konsumen kopi bubuk RANTAU sudah pada kategori loyal karena nilai nilai konsumen yang tidak loyal/suka berpindah-pindah merk kopi atau switcher buyer (34\%) lebih kecil dari nilai konsumen yang setia membeli kopi bubuk Rantau atau Commited buyer( 66\%).

Kata Kunci: Kepuasan; Loyalitas; Kopi Bubuk

\section{Pendahuluan}

Kopi merupakan komoditas strategis yang menjadi ladang bisnis bagi pelaku UMKM karena kopi sudah menjadi kebutuhan dan meminum kopi sudah menjadi kebiasaan bagi sebagian besar masyarakat (Solikatun et al., 2015), sebanyak 66,67\% penikmat kopi meminum kopi termotivasi karena kebutuhan kesehatan (Aini et al., 2021) , tidak hanya laki-laki tapi juga wanita, dan dari berbagai kalangan umur. Hasil penelitian (Putri et al., 2020) usia konsumen kopi terbanyak berkisar antara 20-30 tahun. Munculnya bisnis kopi di seluruh wilayah di Indonesia karena didukung oleh potensi hasil perkebunan kopi yang cukup menyediakan bahan baku kopi dari berbagai jenis seperti Arabika, Robusta, dan kopi luwak.

Provinsi Bengkulu termasuk produsen terbesar kesembilan penghasil kopi nasional Indonesia dari tahun 1997-2021 (Ditjenbun, 2021). Tanaman kopi di propinsi Bengkulu dikelola oleh usaha kopi rakyat dan beberapa perkebunan kopi swasta. Hasil panen kopi banyak dipasarkan secara langsung berupa kopi kulit kering, beras kopi, dan kopi yang sudah diolah menjadi kopi bubuk. Usaha pengolahan kopi bubuk tersebar hampir di seluruh wilayah propinsi Bengkulu, salah satunya adalah di Kabupaten Bengkulu Utara. Dinas Koperasi dan UMKM Kabupaten Bengkulu Utara 2021 mencatat bahwa jumlah home industri kecil dan menengah (IKM) ada 42 industri yang bergerak dibidang pengolahan beras kopi menjadi kopi bubuk. Salah satu kecamatan penghasil kopi bubuk terbanyak di Kabupaten Bengkulu berada di Kecamatan Argamakmur dengan jumlah 
industri sebanyak 22 industri yang bergerak dalam pengolahan beras kopi menjadi kopi bubuk (Desperindak, 2017)

Salah satu merek kopi yang terkenal dan banyak disukai oleh masyarakat di Kecamatan Argamakmur adalah kopi dengan merek "RANTAU". Home industry kopi "RANTAU" ini telah dimulai sejak 1997 atau sudah berjalan selama 24 tahunan dan telah terdaftar di Dinas Kesehatan Bengkulu Utara sebagai Perusahaan Industri Rumah Tangga. Penyebaran kopi "RANTAU" ini telah tersebar ke seluruh Kecamatan Argamakmur mulai dari rumah tanggga, minimarket, warung-warung kecil yang berada di Kecamatan Argamakmur dan juga ke bebarapa kecamatan yang berada dekat dengan Kecamatan Argamakmur seperti Kecamatan Batik Nau dan Kecamatan Padang Jaya. Tidak jarang juga kopi bubuk "RANTAU" ini dijadikan sebagai oleh-oleh bagi orang-orang yang akan pulang kampung ke kampung halamannya.

Banyaknya merek kopi bubuk lain yang terdapat di Kecamatan Argamakmur menuntut para pengusaha kopi untuk terus meningkatkan kualitas produknya agar terus diminati pelanggan. Produsen kopi perlu mengetahui sikap dan perilaku pelanggannya; harus melakukan evaluasi tentang atribut kopi apa yang paling penting yang diharapkan pelanggan; dan harus terus melakukan pemantauan terhadap keinginan, harapan, rasa puas, keloyalan pelanggan terhadap pembelian produk kopi yang dijualnya. Pelanggan yang telah puas terhadap atribut kopi yang diproduksi akan membuat pelanggan tersebut menjadi loyal terhadap produk tersebut walaupun ada perubahan-perubahan yang baik terhadap produk itu. Konsumen yang loyal terhadap suatu produk merupakan hal yang harus dijaga oleh setiap produsen karena merupakan nilai positif bagi perusahaan tersebut. (Rasmikayati et al., 2020) menyatakan para pelaku usaha kopi selain harus mempunyai kemampuan untuk membuat dan memasarkan produknya, juga harus terus mengerti dan mampu untuk memahami keinginan pelanggan karena pembeli merupakan tempat untuk memasarkan produk kopi yang dihasilkan. Oleh sebab itu perlu menganalisis kepuasan dan loyalitas konsumen terhadap suatu produk agar meningkatkan penjualan dan mengembangkan perusahaan. Hal ini menjadi ikon penting yang harus diketahui dan dijaga oleh perusahaan (Yulita, 2014).

Dari uraian latar belakang diatas, tujuan penelitian ini adalah untuk menganalisis bagaimana sikap dan perilaku konsumen, tingkat kepentingan dan kinerja produk, kepuasan, dan loyalitas konsumen terhadap kopi bubuk RANTAU di Kecamatan Argamakmur Kabupaten Bengkulu Utara Provinsi Bengkulu.

\section{Metode}

Tempat dilakukannya penelitian yaitu di usaha kopi bubuk RANTAU yang berada di Kecamatan ArgaMakmur Kabupaten Bengkulu Utara Propinsi Bengkulu. Lokasi dipilih dengan sengaja dengan pertimbangan bahwa Home industri kopi bubuk RANTAU merupakan usaha kopi bubuk yang sangat familiar yang banyak diminati oleh konsumen kopi di Kecamatan Argamakmur Kabupaten Bengkulu Utara dan telah terdaftar di Dinas Kesehatan Kabupaten Bengkulu Utara sebagai usaha yang legal dan sudah beroperasi selama 24 tahun. Dalam penelitian ini data terdiri dari data sekunder dan data primer. Data primer diambil dengan cara mengamati langsung proses produksi, wawancara dengan pelanggan kopi bubuk Rantau, dengan berpedoman pada daftar pertanyaan atau kuesioner yang telah disusun. Data primer terdiri dari data karakteristik reponden, data tentang sikap dan perilaku konsumen, data tentang kepentingan dan kinerja produk, data tingkat kepuasan responden, dan data tentang loyalitas konsumen. Data sekunder dalam penelitian ini terdiri dari gambaran umum usaha kopi bubuk RANTAU yang diperoleh langsung dari pelaku usaha kopi bubuk RANTAU, buku-buku yang berkaitan dengan perilaku, 
kepuasan, dan loyalitas konsumen, jurnal-jurnal penelitian terdahulu yang telah dipublikasi, baik secara online maupun tidak online yang berkaitan dengan penelitian ini untuk mendukung research ini (Priyono et al., 2010).

Sampel penelitian yaitu konsumen kopi bubuk RANTAU diambil secara Accidental sampling. Aksidental sampling merupakan cara untuk mengambil responden yang didasarkan kebetulan, maksudnya siapa saja yang kebetulan ditemukan oleh peneliti yang sedang membeli kopi bubuk RANTAU maka akan dijadikan sebagai responden. (Sugiyono, 2012) menyatakan dalam aksidental sampling, responden tidak ditentukan terlebih dahulu tetapi peneliti mengumpulkan data dari unit sampling yang ditemui di lokasi penelitian pada saat penelitian berlangsung. Kriteria responden dalam penelitian ini adalah konsumen yang dapat mengerti pertanyaan-pertanyaan yang ada pada kuisioner bersedia diwawancarai, konsumen yang pernah membeli dan mengkonsumsi kopi bubuk "RANTAU" minimal 3 kali, dan konsumen berusia 17 tahun keatas karena pada umur ini sudah termasuk golongan dewasa awal, sehingga cenderung sudah bisa mengkonsumsi kopi. Penentuan jumlah responden dilakukan berdasarkan atas metode standar error untuk proporsi dan persentase.

Rumus yang dipakai yaitu :

$$
\begin{aligned}
& n=\frac{Z^{2}[P(1-P)]}{(M O E)^{2}} \\
& n=\frac{(1,96)^{2}[0,5(1-0,5)]}{(0,1)^{2}} \\
& n=96,04 \text { atau } 96 \text { Responden } \\
& \text { Dimana : } \\
& n=\text { Ukuran sampel } \\
& Z=\text { Nilai tabel distribusi normal pada taraf kepercayaan }(95 \%)=1,96 \\
& \mathrm{P}=\text { Peluang }=0,5 \\
& \text { MOE (Margin of Error) : Batas toleransi kesalahan }(10 \%)=0,1
\end{aligned}
$$

.Untuk mengukur Sikap dan Perilaku pelanggan digunakan Desktiptif Analisiys Methode kuantiitative, terutama untuk penelitian eksplorasi guna menggali pandangan atau pelanggan terhadap produk kopi bubuk RANTAU (Marbun et al., 2015). Sugiyono (2016) mendefinisikan metode penelitian deskriptif merupakan teknik untuk menggambarkan fakta yang ada secara sedatail-detailnya yang didasarkan atas kondisi sesungguhnya untuk memberikan gambaran atau keadaan atas objek yang diteliti. Metode analisis Deskriptif Kuantitatif dapat memberikan gambaran tentang objek yang diteliti dan yang dilengkapi dengan data hasil analisis. Adapun data yang dianalisis berupa, Alasan Konsumen Membeli Produk, Frekuensi Konsumen Mengkonsumsi Produk, Jumlah Pembelian Terakhir Produk, Sikap Konsumen Setelah Mengkonsumsi Produk, Niat Konsumen Mengkonsumsi Kembali Produk, dan Perilaku Konsumen Bila Produk Tidak Ada di Lokasi.

Importance Performance Analisis (IPA) atau kinerja yang penting (Sihombing et al., 2019), digunakan untuk mengukur kepentingan dan kinerja dari atribut kopi bubuk Rantau. Menurut (Supriatna \& Affandi, 2021) metode Importance Peroformance Analysis merupakan kerangka kerja sederhana untuk mengevaluasi atribut-atribut produk kopi bubuk dengan melakukan perbandingan antara tingkat kepentingan (harapan) dengan tingkat kinerja produk. Metode IPA memiliki kelebihan dari metode yang lain karena pelaku UMKM kopi dapat merumuskan penangan yang akurat dalam menanggapi rasa belum puas pembeli akan atribut-atribut produk yang dihasilkan yang masih belum sesuai dengan harapan mereka (Ramadhanti \& Marlena, 2021). Kepentingan dan kinerja diukur 
dengan menggunakan skala Likert. Skala Likert menggunakan skala ordinal yang dimanfaatkan untuk mengukur persepsi, sikap, respon, harapan, dan kinerja seseorang atau kelompok terhadap suatu objek (S. Riyanto \& Hatmawan, 2020). Pertanyaaan atau pernyataan bisa dalam positif dan negative. Pertanyaan atau pernyataan yang positif dengan kategori 5 : sangat setuju, 4 : setuju, 3 : nertal, 2 : tidak setuju, dan 1 : sangat tidak setuju dan bentuk pertanyaan atau pernyatan negatif dengan ketegori $1:$ sangat setuju, 2 : setuju, 3 : netral, 4 : tidak setuju, dan 5 : sangat tidak setuju (Pranatawijaya et al., 2019).

Hasil pengukuran tingkat kepentingan terhadap atribut dan kinerja atribut kemudian digambarkan ke dalam Diagram Karteius, yang terdiri atas 4 kuadran. (Riyanto, 2015) menyatakan Diagram kartesius Importance Performance Analysis terdapat 2 sumbu, dimana sumbu yang vertikal $(\mathrm{X})$ merupakan tingkat penilaian kinerja atribut dan sumbu horizontal (Y) merupakan tingkat kepentingan terhadap atribut. Titik perpotongan garis $\mathrm{X}$ dan $\mathrm{Y}$ merupakan tempat pertemuan nilai nilai tingkat kepentingan rata-rata dan nilai kinerja rata-rata atribut kopi bubuk RANTAU.

1. Kuadran 1 (Prioritas Utama)

Pada kuadran 1 akan muncul beberapa atribut yang menurut pembeli tingkat kepentingannya tinggi, akan tetapi kinerja atribut masih kurang. Atribut-atribut yang muncul pada kuadran 1 merupakan atribut-atribut yang harus diprioritaskan untuk diperbaiki oleh usaha kopi bubuk RANTAU sangat atribut ini sangat penting bagi pembeli dan belum memenuhi harapan pembeli.

2. Kuadran 2 (Pertahankan Prestasi)

Pada kuadran 2 terdapat atribut-atribut dari kopi bubuk Rantau yang menurut pembeli atribut ini penting dan kinerja atributnya sudah memenuhi harapan pembeli atau kinerjanya sudah baik. Atribut-atribut ini harus dipertahankan kinerja oleh pelaku usaha kopi bubuk RANTAU.

3. Kuadran 3 (Prioritas Rendah)

Kuadran 3 memuat atribut-atribut kopi RANTAU yang tingkat kepentingannya menurut pembeli kurang penting dan kinerjanya juga rendah.

4. Kuadran 4 (Berlebihan)

Kuadran 4 memuat atribut-atribut kopi RANTAU yang menurut konsumen tingkat kepentingan terhadap atribut ini rendah, namun pelaksanaannya atau kinerjanya oleh pelaku usaha kopi bubuk RANTAU dianggap berlebihan.

Dalam menganalisis seberapa besarnya nilai kepuasan pelanggan atau pembeli digunakan metode Indeks Kepuasan Konsumen atau Customer Satisfaction Index (CSI). Interpretasi dari CSI adalah angka yang menggambarkan seberapa besarnya tingkatan kepuasan pelanggan kopi bubuk RANTAU (\%) (Sihombing et al., 2019). Indeks Kepuasan Konsumen dipergunakan untuk mengevalusi tingkat kepuasan pembeli terhadap kopi bubuk RANTAU secara keseluruhan. Angka tertinggi dari indeks Kepuasan Konsumen adalah $100 \%$. Rentang nilai Indeks Kepuasan Konsumen adalah sangat puas $=(81 \%$ sampai dengan $100 \%)$, puas $=(66 \%$ sampai $80 \%)$, cukup puas $=(51 \%$ sampai dengan $65 \%)$, kurang puas $=(35 \%$ sampai dengan $50 \%)$, dan tidak puas $=(0 \%$ sampai dengan 34\%) (AT et al., 2020). Langah-langkah dalam analisis CSI sebagai berikut (Maiyanti et al., 2010):

1. Cari nilai persentase Weighting Factor (WF), dengan cara membandingkan rata-rata tingkat kepentingan (means satisfaction score) kopi bubuk RANTAU dengan total nilai keseluruhan tingkat (means satisfaction satisfaction total) rata-rata kepentingan kopi bubuk RANTAU.

Rumus : WF $=\frac{M S S}{\text { Total MSS }}$ 
2. Cari atau hitung nilai Weighted Score (WS), dengan cara mengalikan rata-rata tingkat kinerja kopi bubuk RANTAU atau mean satisfaction score (MSS) atribut dengan WF masing-masing atribut.

Rumus : WS = MSS x WF

3. Cari atau hitung nilai Weighted Total (WT), dengan cara mentotalkan WS dari semua atribut produk kopi bubuk RANTAU.

4. Cari atau hitung indeks kepuasan atau satisfaction indeks, dengan cara WT dibagi dengan skala tertinggi atau high scale (HS), kemudian dikali $100 \%$

Rumus : CSI $=\frac{\mathrm{WT}}{\mathrm{HS}} \times 100 \%$

Tingkat kepuasan pelanggan Kopi Bubuk RANTAU secara total dengan kriteria sebagi berikut (Patimah et al., 2016)

Tabel 1. Rentang Skala dan Interpretasi Analisis Customer Satisfaction Index (CSI)

\begin{tabular}{cc}
\hline Rentang Skala CSI $(\boldsymbol{\%})$ & Interprestasi \\
\hline $0-20$ & sangat tidak puas \\
$21-40$ & tidap puas \\
$41-60$ & cukup puas \\
$61-80$ & puas \\
$81-100$ & sangat puas \\
\hline
\end{tabular}

Sumber: Fatimah, 2016

Tingkat loyalitas pembeli digambarkan dalam piramida loyalitas dengan kategori dalam \% yang diukur dengan switcher buyer, habitual buyer, satisfied buyer, liking the brand dan comited buyer konsumen pada satu merek produk (Durianto,2004) dalam (Fitriani et al., 2018)

\section{Switcher Buyer}

Switcher Buyer merupakan pembeli yang memiliki tingkat layalitas rendah, pembeli ini akan berpindah apabila terjadi kenaikan harga kopi, tidak terlalu mempermasalahkan merk kopi, dan apabila diminta pendapatnya tentang apakah menganti merk kopi apabila kopi tersebut harganya naik, maka pembeli ini akan menjawab selalu atau sering (Fitriani et al., 2018) dan jika ditanya apakah membeli suatu merk produk kopi sangat dipengaruhi oleh harganya, maka akan menjawab sangat setuju atau setuju.

Tabel 2. Perhitungan Switcher Buyer

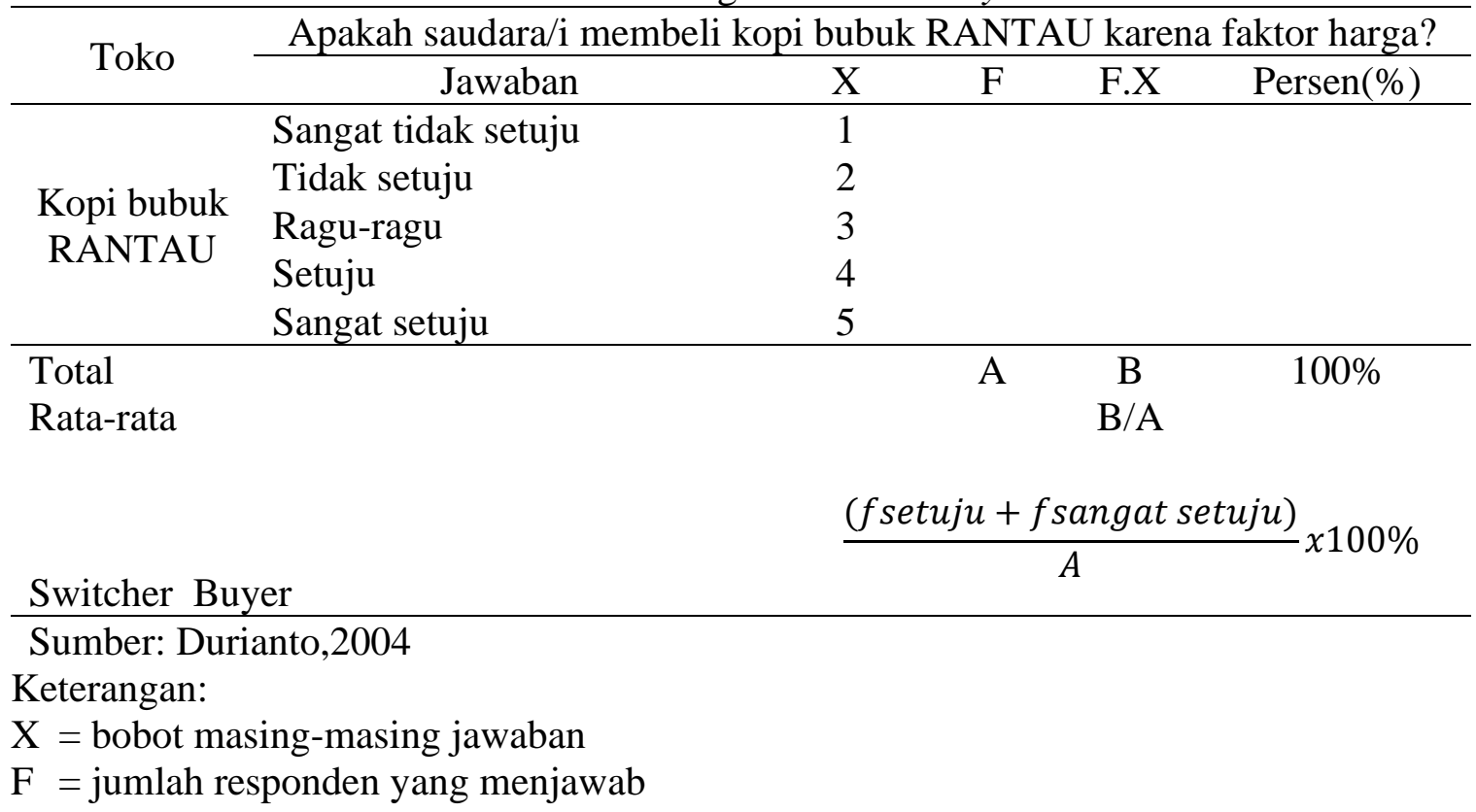


$\%=$ persentase responden yang menjawab setuju dan sangat setuju

$$
\text { interval }=\frac{\text { nilai tertinggi }- \text { nilai terendah }}{\text { banyak kelas }}=\frac{5-1}{5}=0,80
$$

Setelah besarnya interval diketahui, kemudian dibuat rentang skala sehingga dapat diketahui di mana letak rata-rata penilaian responden terhadap setiap unsur variasinya. Rentang skala tersebut adalah:

$1,00-1,80=$ sangat tidak setuju

$1,81-2,60=$ tidak setuju

$2,61-3,40=$ cukup setuju

$3,41-4,20=$ setuju

$4,21-5,00=$ sangat setuju

\section{Habitual Buyer}

Pembeli yang loyal membeli karena mereka sudah terbiasa atau faktor kebiasaan membeli dan mengkonsumsi kopi bubuk RANTAU disebut Habitual buyer, bagi konsumen yang sudah terbiasa membeli kopi bubuk RANTAU tidak ada alasan lain untuk berpindah membeli merk produk kopi lain dan tidak mau mengeluarkan biaya karena beralih merk kopi. Responden yang membeli karena kebiasaan menjawab 'setuju' dan 'sangat setuju' (Lestari et al., 2020)

Tabel 3. Perhitungan Habitual Buyer

\begin{tabular}{|c|c|c|c|c|c|}
\hline \multirow[t]{2}{*}{ Toko } & \multicolumn{5}{|c|}{$\begin{array}{l}\text { Apakah saudara/i membeli kopi bubuk RANTAU karena sudah menjadi } \\
\text { kebiasaan? }\end{array}$} \\
\hline & Jawaban & $X$ & $\mathrm{~F}$ & F.X & Persen $(\%)$ \\
\hline \multirow{5}{*}{$\begin{array}{c}\text { Kopi } \\
\text { bubuk } \\
\text { RANTAU }\end{array}$} & Sangat tidak setuju & 1 & & & \\
\hline & Tidak setuju & 2 & & & \\
\hline & Ragu-ragu & 3 & & & \\
\hline & Setuju & 4 & & & \\
\hline & Sangat setuju & 5 & & & \\
\hline
\end{tabular}

\section{Satisfied Buyer}

Satisfied buyer merupakn pembeli yang loyak membeli kopi bubuk Rantau karena puas dengan produk, baik rasa, aroma, harga, kemudahan memperoleh produk, atau atribut lain yang terkandung dalam kopi, namun demikian pembeli ini masih akan berpindah ke merk kopi yang lain dan bersedia menanggung biaya untuk berpindah merk (switching cost), baik dalam waktu, uang atau resiko sehubungan dengan upaya untuk melakukan pergantian ke merek lain. Satisfied buyer dihitung berdasarkan jawaban puas dan sangat puas.

Tabel 4. Perhitungan Satisfied Buyer

\begin{tabular}{clcccc}
\hline \multirow{2}{*}{ Toko } & \multicolumn{2}{l}{$\begin{array}{l}\text { Apakah saudara/i menemukan kepuasan dalam mengkonsumsi kopi } \\
\text { bubuk RANTAU }\end{array}$} \\
\cline { 2 - 6 } & \multicolumn{1}{c}{ Jawaban } & X & F & F.X & Persen(\%) \\
\hline \multirow{3}{*}{ Kopi bubuk } & Sangat tidak puas & 1 & & & \\
RANTAU & Biasa & 2 & & & \\
& Puas & 3 & & & \\
& Sangat puas & 4 & & & \\
\hline
\end{tabular}




\section{Liking The Brand}

Liking the brand merupakan pelanggan yang sungguh-sungguh menyukai kopi bubuk RANTAU. Para pembeli pada tingkat ini disebut sahabat merek, karena terdapat perasaan emosional dalam menyukai merek. Responden yang termasuk dalam kategori ini adalah responden yang menjawab suka dan sangat suka.

Tabel 5. Perhitungan Liking The Brand

\begin{tabular}{clllll}
\hline \multirow{2}{*}{ Toko } & \multicolumn{4}{l}{ Apakah saudara/i benar-benar menyukai } & kopi bubuk RANTAU? \\
\cline { 2 - 5 } & Jawaban & $X$ & F & F.X & Persen(\%) \\
\hline \multirow{3}{*}{ Kopi } & Sangat tidak suka & 1 & & & \\
bubuk & Bidak suka & 2 & & & \\
RANTAU & Suka & 3 & & & \\
& Sangat suka & 4 & & \\
\hline
\end{tabular}

\section{Commited Buyer}

Committed buyer merupakan tingkat teratas dalam piramida loyalitas yaitu para pelanggan yang setia terhadap merek. Pelanggan yang setia akan bersedia untuk menyarankan atau merekomendasikan produk untuk dibeli.

Tabel 6. Perhitungan Commited Buyer

\begin{tabular}{|c|c|c|c|c|c|}
\hline \multirow[t]{2}{*}{ Toko } & \multicolumn{5}{|c|}{$\begin{array}{l}\text { Apakah saudara/i akan tetap membeli kopi bubuk RANTAU apabila } \\
\text { berganti nama dan tetap merekomendasikan kepada orang lain? }\end{array}$} \\
\hline & Jawaban & $X$ & $\mathrm{~F}$ & F.X & Persen(\%) \\
\hline \multirow{5}{*}{$\begin{array}{l}\text { Kopi bubuk } \\
\text { RANTAU }\end{array}$} & Sangat tidak sutuju & 1 & & & \\
\hline & Tidak setuju & 2 & & & \\
\hline & Ragu-ragu & 3 & & & \\
\hline & Setuju & 4 & & & \\
\hline & Sangat setuju & 5 & & & \\
\hline
\end{tabular}

Bila nilai presentase switcher semakin kecil dan nilai presentase comited buyer semakin besar, maka piramidanya semakin bagus berbentuk piramida terbalik, yang berarti semakin tinggi loyalitas konsumen terhadap merek tersebut.

\section{Hasil dan Pembahasan}

\section{Karakteristik Konsumen Kopi Bubuk RANTAU}



Gambar 1. Jenis Kelamin Responden

Konsumen terbanyak mengkonsumsi kopi bubuk RANTAU adalah laki-laki sebanyak 93 orang atau sebanyak 97\%. Konsumen yang berjenis kelamin perempuan hanya 3 orang atau sebesar 3\%. Dari penelitian ini disimpulkan bahwa mayoritas konsumen kopi bubuk RANTAU adalah laki-laki. Penelitian ini sejalan dengan hasil penelitian (Sausan et al, 2021) bahwa laki-laki merupakan pelanggan paling banyak kopi bubuk Kapal Api di Kota Surakarta. 


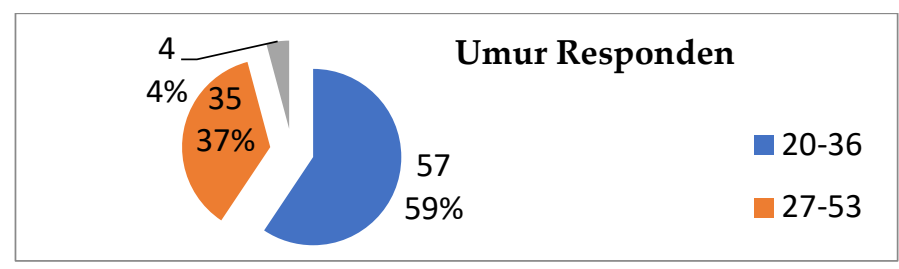

Gambar 2. Umur Responden

Rata-rata umur responden kopi bubuk RANTAU adalah 36 tahun. Umur konsumen pengkonsumsi kopi pada rentang (20-36 tahun) sebanyak 57 orang atau sebesar 59\%. Secara rata-rata tergambar bahwa rata-rata responden berada pada usia pengkonsumsi kopi bubuk RANTAU yaitu berumur 36 tahun.

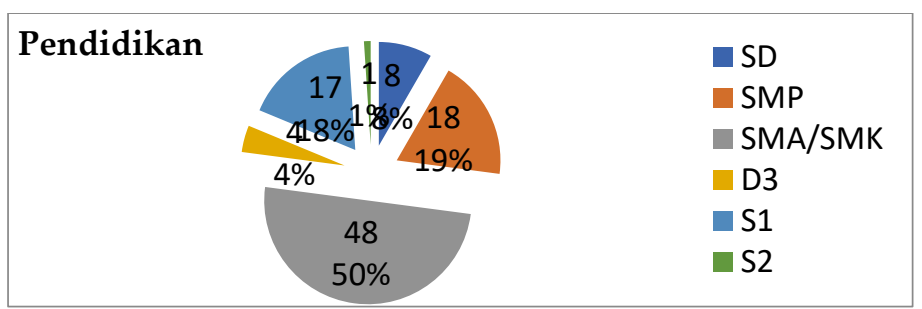

Gambar 3. Tingkat Pendidikan Responden

Tingkat pendidikan konsumen paling banyak lulusan SMA/STM sebanyak 48 orang atau sebesar 50,00\%. Sedangkan tingkat pendidikan konsumen yang paling sedikit adalah Magister (S2) sebanyak 1 orang atau sebesar 1\%. Hasil penelitian (Sausan, et al, 2021) bahwa konsumen paling banyak mengkonsumsi kopi adalah dengan tingkat pendikikan Sarjana (S1), dengan semakin tingginya tingkat pendidikan ini pengetahuan dan informasi yang dimiliki konsumen juga banyak sehingga tingkat selektifnya untuk membeli kopi semakin tinggi.

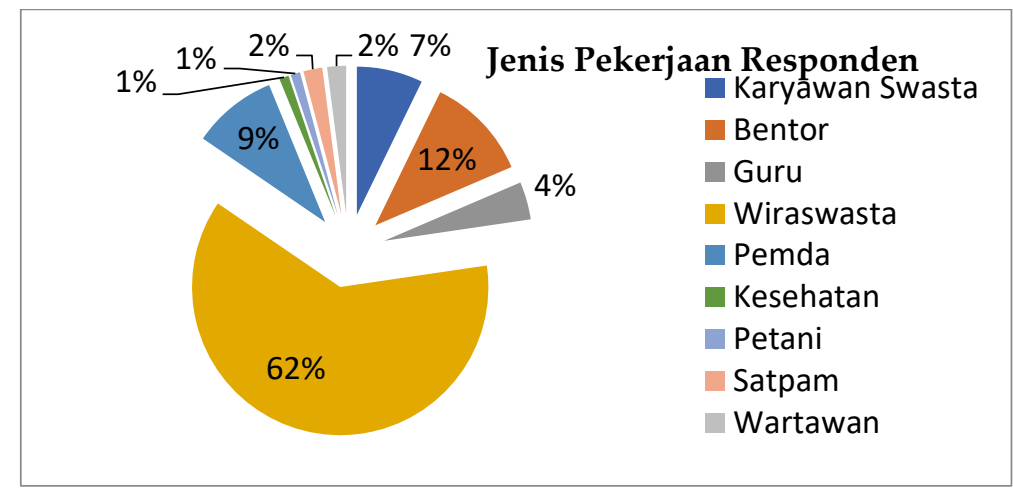

Gambar 4. Umur Responden

Jumlah konsumen kopi bubuk RANTAU sebagian besar, yaitu $62 \%$ bekerja sebagai wiraswasta dan paling sedikit berasal dari konsumen yang bekerja sebagai petani, kesehatan (perawat) masing-masing sebesar $1 \%$.

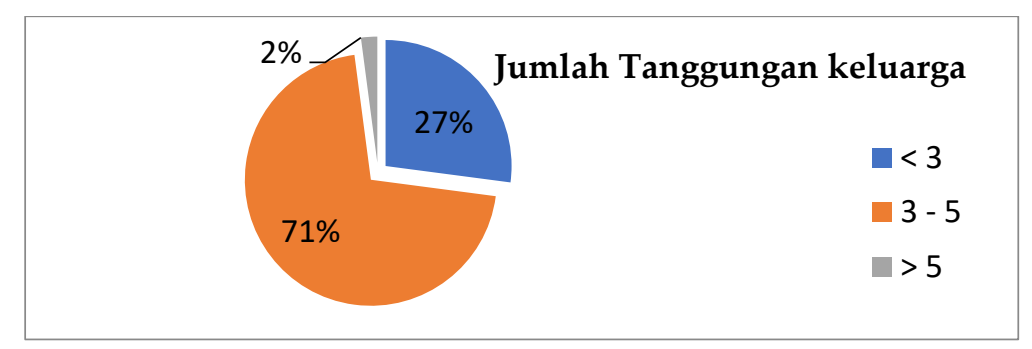

Gambar 5. Jumlah Anggota Keluarga Responden 
Rata-rata jumlah anggota keluarga konsumen kopi bubuk RANTAU adalah 3 orang. Jumlah anggota keluarga konsumen kopi bubuk RANTAU terbanyak dikategorikan 3-5 orang dengan jumlah responden sebanyak 68 orang atau sebesar $71 \%$.

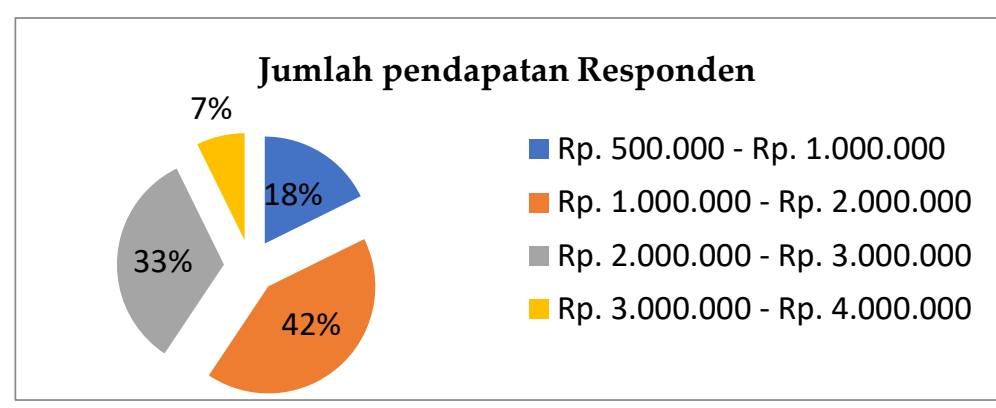

Gambar 6. Pendapatan Responden

Sebagian besar responden kopi bubuk Rantau, yaitu 42\% memiliki pendapatan perbulan berkisar antara Rp. 1.000.000 - Rp. 2.000.000 dan yang paling sedikit, yaitu 7\% yang memiliki pendapatan per bulan berkisar antara Rp. 3.000.000 - Rp. 4.000 .000

\section{Sikap Pembelian Konsumen Kopi Bubuk RANTAU}

Proses pembelian dilakukan secara sadar maupun tidak sadar oleh pelanggan. Tahapan-tahapan yang dilalui oleh pelanggan untuk membuat keputusan pembelian, yaitu pengenalan kebutuhan, pencarian informasi, evaluasi alternative, keputusan pembelian, dan evaluasi pasca pembelian (Rumondang et al., 2020)

Tabel 7. Alasan Konsumen Membeli Kopi Bubuk RANTAU

\begin{tabular}{clcc}
\hline No & \multicolumn{1}{c}{ Alasan } & Jumlah jawaban & Persentase (\%) \\
\hline 1 & Rasa yang enak & 74 & 77,08 \\
2 & Harga yang terjangkau & 13 & 13,54 \\
3 & Mudah diperoleh & 9 & 9,38 \\
\hline & Jumlah & 96 & 100 \\
\hline
\end{tabular}

Dari Tabel 6 terlihat bahwa alasan utama konsumen membeli kopi bubuk RANTAU adalah karena rasanya enak, yaitu sebanyak 74 orang responden atau $77,08 \%$. Sisanya sebanyak 13,54\% konsumen membeli dengan alasan harga terjangkau, dan 9,38\% membeli karena mudah diperoleh. Hasil penelitian ini sejalan dengan hasil penelitian (Sausan et al, 2021) bahwa alasan terbesar konsumen kopi bubuk Cap Kapal Api di Surakarta karena cita rasa yang sesuai dengan selera konsumen.

Frekuensi waktu rata-rata konsumen dalam membeli kopi bubuk RANTAU disajikan pada tabel 8 .

Tabel 8. Frekuensi Rata-rata Mengkonsumsi Kopi Bubuk RANTAU

\begin{tabular}{ccccc}
\hline No & $\begin{array}{l}\text { Frekuensi Rata-rata } \\
\text { Mengkonsumsi } \\
\text { (kali/hari) }\end{array}$ & Jumlah (orang) & Persentase (\%) & $\begin{array}{l}\text { Rata-rata } \\
\text { (kali/hari) }\end{array}$ \\
\hline 1 & 1 & 2 & 2,08 & \\
2 & 2 & 18 & 18,75 & \\
3 & 3 & 52 & 54,17 & \\
4 & 4 & 13 & 13,54 & \\
5 & 5 & 9 & 9,38 & \\
6 & 6 & 1 & 1,04 & \\
7 & 7 & 1 & 1,04 & \\
\hline \multicolumn{5}{r}{} \\
\hline
\end{tabular}


Frekuensi rata-rata mengkonsumsi kopi oleh konsumen terbanyak adalah 3 kali sehari dengan persentase sebesar 54,17\%. Hal ini menggambarkan bahwa konsumen yang mengkonsumsi kopi bubuk RANTAU sudah menganggap kopi sebagai kebutuhan seharihari, sehingga jika tidak minum kopi sehari konsumen merasakan ada yang kurang. Frekuensi ini juga akan mempengaruhi banyaknya pembelian yang dilakukan konsumen yaitu jumlah pembelian terakhir yang dilakukan konsumen kopi bubuk RANTAU sebanyak $0,25 \mathrm{Kg}$ atau sebesar 56,25\%. Hal ini disebabkan oleh frekuensi rata-rata mengkonsumsi konsumen yaitu sebanyak 3 kali karena bagi konsumen mengkonsumsi kopi sudah menjadi rutinitas setiap harinya sudah seperti kebutuhan pokok yang tidak bisa ditinggalkan, dan juga biar cepat habis sehingga bisa beli lagi dengan hasil gilingan kopi yang baru.

Tabel 9. Sikap dan Niat Konsumen untuk Mengkonsumsi Kembali Kopi Bubuk RANTAU.

\begin{tabular}{clccc}
\hline No. & Sikap dan Niat Untuk Membeli Kembali & Jumlah (orang) & Persentase (\%) \\
\hline 1 & Ya & 96 & 100 \\
2 & Tidak & & 0 & 0 \\
\hline & & Total & $\mathbf{9 6}$ & $\mathbf{1 0 0}$ \\
\hline
\end{tabular}

Dari tabel 9 diketahui bahwa pembeli kopi bubuk Rantau semuanya (100\%) memiliki sikap dan niat untuk membeli kembali kopi ini karena mereka puas. Pelanggan yang merasa puas setelah membeli produk.

Tabel 10. Perilaku Konsumen Apabila Kopi Bubuk RANTAU Tidak Tersedia.

\begin{tabular}{clcc}
\hline \multirow{2}{*}{ No. } & $\begin{array}{c}\text { Tindakan Apabila Kopi Bubuk } \\
\text { RANTAU Tidak Ada }\end{array}$ & Jumlah (Orang) & Persentase (\%) \\
\hline 1 & Pergi Ketempat Lain & 49 & 51,04 \\
2 & Beli Produk Sejenis & 39 & 40,63 \\
3 & Tidak Jadi Beli & 8 & 8,33 \\
\hline & Total & $\mathbf{9 6}$ & $\mathbf{1 0 0}$ \\
\hline
\end{tabular}

Perilaku konsumen apabila produk kopi bubuk RANTAU jika tidak ada bahwa sebanyak 49 orang atau 51,04\% konsumen menjawab akan membeli kopi bubuk RANTAU ke tempat lain. Berarti konsumen kopi bubuk RANTAU sudah percaya dan puas akan kopi bubuk RANTAU sehingga konsumen mau pergi atau mencari ke tempat lain untuk membeli kopi bubuk yang diinginkan.

\section{Analisis Tingkat Kepentingan dan Tingkat Kinerja Atribut Usaha Kopi Bubuk RANTAU}

Analisis IPA dipergunakan untuk mengidentifikasi faktor-faktor kinerja yang harus diakomodir pelaku usaha kopi bubuk Rantau untuk memenuhi kepuasan dan meningkatkan loyalitas pelanggannya (Fipiana et al., 2021).Perhitungan tingkat kepentingan dan tingkat kinerja dapat dilihat pada Tabel 11.

Tabel 11. Perhitungan Rata-rata dari Penilaian Tingkat Kepentingan dan Kinerja Atribut Kopi Bubuk RANTAU.

\begin{tabular}{lllll}
\hline No & Nama Atribut & $\begin{array}{l}\text { Kode } \\
\text { Atribut }\end{array}$ & $\begin{array}{l}\text { Skor Rata-rata } \\
\text { Tingkat } \\
\text { Kepentingan } \\
(\text { Yi/n) }\end{array}$ & $\begin{array}{l}\text { Tingkat } \\
\text { Kinerja } \\
\text { (Xi/n) }\end{array}$ \\
\hline 1 & Rasa & A1 & 3,84 & 3,47 \\
2 & Tekstur & A2 & 3,39 & 3,12 \\
3 & Aroma & A3 & 4,00 & 3,83
\end{tabular}




\begin{tabular}{lllll}
4 & Harga & A4 & 3,63 & 3,56 \\
5 & Ukuran Kemasan & A5 & 3,56 & 2,77 \\
6 & Kondisi Kemasan & A6 & 4,00 & 3,85 \\
7 & Kemenarikan Kemasan & A7 & 3,36 & 3,34 \\
8 & Lokasi Pembelian & A8 & 3,98 & 4,02 \\
9 & Kemudahan Peroleh Produk & A9 & 4,00 & 4,01 \\
10 & Tanggal Kadaluarsa & A10 & 4,24 & 1,11 \\
\hline Jumlah & & $\mathbf{3 7 , 9 9}$ & $\mathbf{3 3 , 0 8}$ \\
\hline Rata-rata & & $\mathbf{3 , 8 0}$ & $\mathbf{3 , 3 1}$ \\
\hline
\end{tabular}

Berdasarkan tabel 11, terlihat bahwa tingkat kepentingan dari setiap atribut-atribut kopi bubuk RANTAU secara keseluruhan relatif lebih besar dibandingkan dengan tingkat kinerja konsumen yaitu dengan rata-rata nilai tingkat kepentingan sebesar 3,80 dan ratarata nilai tingkat kinerja sebesar 3,31. Hal ini menunjukkan bahwa kinerja atribut yang ditawarkan kopi bubuk RANTAU secara keseluruhan belum dapat memenuhi kepentingan/harapan seluruh konsumennya. Sehingga, hal tersebut akan mempengaruhi besarnya nilai tingkat kepuasan konsumen akan kopi bubuk RANTAU.

Hasil evaluasi tingkat kepentingan dan kinerja dari masing-masing atribut kopi bubuk RANTAU agar mempunyai makna perlunya diagram kartesius dan dari diagram tersebut akan terlihat atribut yang perlu diprioritaskan perbaikan kinerjanya dan perlu dipertahankan karena kinerjanya sudah baik (Diyahya et al., 2016). Rata-rata tingkat kepentingan yaitu 3,80 dan nilai total rata-rata tingkat kinerja yaitu 3,31. Untuk lebih jelasnya dapat dilihat pada gambar 7 .

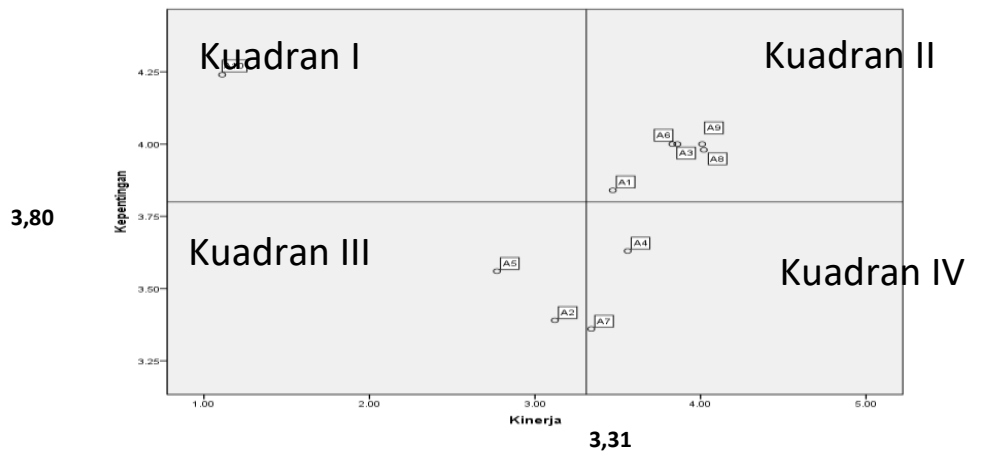

Gambar 7. Diagram Kartesius Importance and Performance Analysis (IPA)

\section{a. Prioritas Utama (Kuadran I)}

Pada Kuadran I, atribut kopi bubuk RANTAU pada wilayah ini merupakan prioritas utama untuk ditingkatkan kinerjanya karena atribut ini penting bagi pelanggan. Atribut kopi bubuk RANTAU yang perlu diprioritaskan peningkatan kinerjanya adalah : Tanggal kadaluarsa (A10), sebab pada produk kopi bubuk RANTAU belum terdapat tanggal kadaluarsa sedangkan itu penting bagi konsumen karena itu melengkapi informasi pada produk kopi bubuk RANTAU.

b. Pertahankan Prestasi (Kuadran II)

Pada Kuadran II ini terdapat atribut-atribut yang sudah memenuhi harapan pembeli dan kinerjanya telah dipenuhi produsen kopi bubuk RANTAU dengan baik dan perlu untuk dipertahankan. Atribut ini antara lain Rasa (A1), Aroma(A3), Kondisi Kemasan (A6), Lokasi Pembelian (A8), Kemudahan Peroleh Produk (A9). 


\section{c. Prioritas Rendah (Kuadran III)}

Atribut-atribut produk kopi bubuk RANTAU yang muncul di Kuadran III menurut pembeli kurang penting dan tingkat kinerjanya rendah. Atribut yang masuk pada kuadran tiga yaitu: Tekstur (A2), dan Ukuran Kemasan (A5).

\section{d. Berlebihan (Kuadran IV)}

Atribut-atribut kopi bubuk RANTAU di Kuadran IV merupakan atribut yang menurut pembeli kurang penting, akan tetapi kinerjanya sudah berlebih. Atribut tersebut adalah Harga Kopi (A4) dan Kemenarikan Kemasan (A7).

\section{Indeks Kepuasan Konsumen atau Costumer Satisfaction Index (CSI)}

Nilai indeks kepuasan pelanggang diukur dari pendapat dan penilaian konsumen yang sebelumnya telah diperoleh nilai rataan dari masing-masing atribut baik dari aspek kinerja atau kepentingan. Dengan melakukan pengukuran ini, maka akan dapat diketahui pembeli atau pelanggan sudah puas, belum puas, atau tidak puas dengan kopi bubuk RANTAU. Adapun hasil perhitungan tingkat kepuasan konsumen kopi bubuk RANTAU terlihat pada tabel 12 berikut :

Tabel 12.Tingkat Kepuasan Konsumen Kopi Bubuk Rantau

\begin{tabular}{|c|c|c|c|c|c|}
\hline No & Atribut & $\begin{array}{l}\text { Tingkat } \\
\text { Kepentingan } \\
(\mathrm{Y})\end{array}$ & $\begin{array}{l}\text { Weighted } \\
\text { Factor } \\
\quad(\mathrm{WF})\end{array}$ & $\begin{array}{c}\text { Tingkat } \\
\text { Kinerja } \\
(\mathrm{X}))\end{array}$ & $\begin{array}{l}\text { Weighted } \\
\text { Score } \\
\quad(\mathrm{WS})\end{array}$ \\
\hline 1 & Rasa & 3,84 & 10,10 & 3,47 & 0,35 \\
\hline 2 & Tekstur & 3,38 & 8,91 & 3,11 & 0,28 \\
\hline 3 & Aroma & 4,00 & 10,53 & 3,83 & 0,41 \\
\hline 4 & Harga & 3,63 & 9,56 & 3,56 & 0,34 \\
\hline 5 & Ukuran Kemasan & 3,56 & 9,36 & 2,77 & 0,26 \\
\hline 6 & Kondisi Kemasan & 4,00 & 10,53 & 3,85 & 0,41 \\
\hline 7 & Kemenarikan & & & & \\
\hline & Kemasan & 3,36 & 8,85 & 3,34 & 0,30 \\
\hline 8 & Lokasi Pembelian & 3,98 & 10,47 & 4,02 & 0,42 \\
\hline 9 & Kemudahan & & & & \\
\hline & Peroleh Produk & 4,00 & 10,53 & 4,01 & 0,42 \\
\hline 10 & Tanggal Kadaluarsa & 4,23 & 11,16 & 1,11 & 0,12 \\
\hline & Total & 37,99 & 100 & 33,08 & \\
\hline \multicolumn{5}{|c|}{ Weighted Total (WT) } & 3,30 \\
\hline \multicolumn{5}{|c|}{ Costumer Statisfaction Index (CSI) } & $66 \%$ \\
\hline \multicolumn{5}{|c|}{ Interpretasi } & Puas \\
\hline
\end{tabular}

Dari tabel 12 dapat diketahui bahwa tingkat kepuasan konsumen atau Costumer Satisfaction Indeks (CSI) sebesar 66\%. Nilai ini terletak pada rentang $61 \% \leq \mathrm{CSI} \geq 80 \%$ (puas) yang artinya konsumen kopi bubuk RANTAU puas dengan kinerja atribut produk bubuk RANTAU secara keseluruhan. Meskipun demikian, pelaku usaha kopi bubuk RANTAU masih harus terus meningkatkan kinerja atribut produk kopi bubuk yang dihasilkan agar mencapai tingkat kepuasan konsumen yang baru terpenuhi $66 \%$ bisa menjadi $100 \%$ (sangat puas) karena pelaku usaha kopi bubuk RANTAU masih memiliki nilai kepuasan konsumen sebesar 34\% yang belum terpenuhi. Hal senada juga diungkapkan oleh (Wutabisu et al., 2021), dari hasil penelitian tingkat kepuasan konsumen terhadap kopi Poso meskipun nilai indeks kepuasan konsumen sudah 83,22\% yang berarti sudah sangat puas, namun demikian karena belum mencapai $100 \%$ maka upaya perbaikan mutu produk harus terus dilakukan agar kepuasan konsumen meningkat. Dari tabel 2 juga dapat diketahui bahwa atribut yang disukai konsumen kopi bubuk RANTAU adalah lokasi 
pembelian, kemudahan memperoleh produk, aroma kopi, kondisi kemasan, rasa, dan harga kopi.

Hasil penelitian (Putri et al., 2020) di agroindustri kopi bubuk Cap Jempol di Bandar Lampung, juga menunjukkan konsumen telah puas dengan produk kopi bubuk Cap Jempol yang digambarkan dengan nilai indeks kepuasan konsumen sebesar 72,87\% dan kopi Cap Jempol ini disukai karena memiliki aroma yang khas, harga yang terjangkau sesuai dengan produk yang ditawarkan, kemasan, kemudahan memperoleh produk, komposisi produk, tanggal kadaluarsa, tekstur, dan warna.

\section{Tingkat Loyalitas Konsumen Terhadap Kopi Bubuk RANTAU}

Tingkat Loyalitas konsumen dapat diukur berdasarkan kriteria tingkatan piramida loyalitas. Adapun tingkatan-tingkatan tersebut terdiri dari switcher buyer, yaitu konsumen kopi bubuk RANTAU yang tidak loyal, sering melakukan pembelian berpindah karena faktor perubahan harga; habitual buyer, yaitu konsumen yang loyal karena sudah terbiasa membeli produk kopi bubuk RANTAU; satisfied buyer, yaitu konsumen yang loyal terhadap kopi bubuk RANTAU karena mereka puas dengan produk tersebut; likingthe brand, yaitu konsumen yang benar-benar menyukai kopi bubuk RANTAU karena sudah berpengalaman mengkonsumsi kopi ini; dan commited buyer, yaitu konsumen yang loyal dan selalu membeli kopi bubuk Rantau dan memiliki kesediaan untuk menyarankan kopi ini ke orang lain untuk di konsumsi. Piramida loyalitas konsumen kopi bubuk RANTAU di Kecamatan Argamakmur dapat dilihat pada gambar 8.

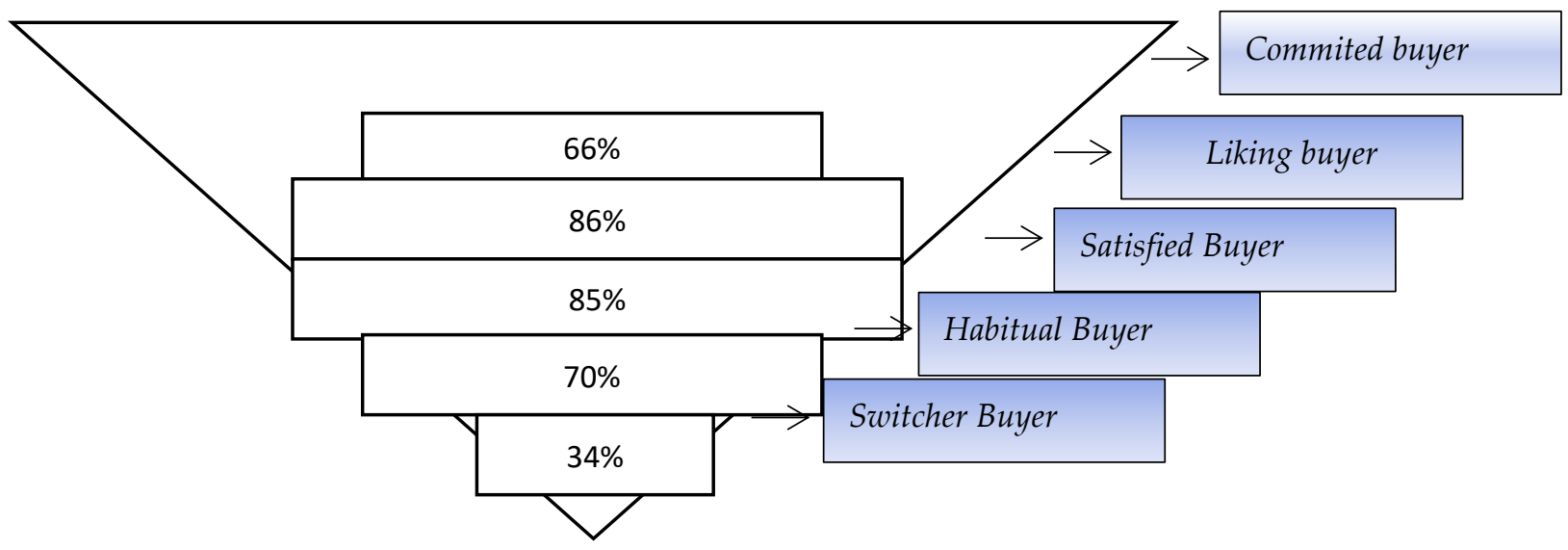

Gambar 8. Loyalitas Konsumen Produk Kopi Bubuk RANTAU

Dari gambar 8. terlihat bahwa kondisi kopi bubuk RANTAU baik karena bentuk piramida semakin keatas semakin melebar. Pada tingkatan loyalitas konsumen, konsumen yang merupakan pelanggan setia atau commited buyer sebanyak 66\%, pelanggan yang benar-benar suka atau liking the brand buyer sebanyak $86 \%$, pelanggan yang puas atau satisfied buyer sebanyak $85 \%$, pelanggan yang membeli karena kebiasaan atau habitual buyer sebanyak $70 \%$, dan pelanggan yang tidak loyal atau switcher buyer sebanyak $34 \%$.

\section{Commited Buyer}

Commited buyer merupakan tingkat loyalitas tertinggi konsumen dimana pembeli setia membeli dan mengkonsumsi kopi bubuk RANTAU dan bersedia untuk memperkenalkan kopi bubuk RANTAU kepada konsumen kopi lainnya. Dari hasil perhitungan menunjukkan bahwa konsumen kopi bubuk RANTAU di Kecamatan Argamakmur pada tingkat commited buyer (pembeli yang setia) sebesar $66 \%$ nilai ratarata commited buyer adalah 3,66 yang terletak pada kategori setuju $(3,41-4,20)$ yang bermakna bahwa pembeli kopi bubuk RANTU setuju untuk merekomendasikan atau 
membantu menyebarluaskan informasi tentang kopi bubuk RANTAU di kecamatan Argamakmur kepada orang lain. Pelanggan kopi bubuk RANTAU di Kecamatan Argamakmur sudah pada tahap pembeli loyal ,dimana persentase commited buyer $66 \%$ lebih besar dari switcher buyer 34\%. Akan tetapi, perusahaan kopi bubuk RANTAU harus terus meningkatkan tingkat pembeli yang setia sehingga piramida loyalitas yang ideal yang diinginkan dapat tercapai.

\section{Liking The Brand Buyer}

Gambar 8 menunjukkan konsumen yang benar-benar menyukai kopi bubuk RANTAU dan enggan untuk beralih ke merek kopi bubuk lainnya yang ada di kecamatan Argamakmur sebanyak 86 persen. Rata-rata nilai liking the brand buyer adalah 4,05 yang berada kategori setuju (rentang 3,41-4,20), bermakna bahwa pelangga merespon setuju dengan pertanyaan mereka benar-benar menyukai kopi bubuk RANTAU di Kecamatan Argamakmur. Hal ini berkaitan dengan kopi bubuk RANTAU yang merupakan kopi yang sudah ada sejak lama dan telah tersebar ke Kecamatan Argamakmur. Berkembangnya perusahaan ini karena di dukung dengan konsumen yang menyukai brand produk.

\section{Satisfied Buyer}

Gambar 8 menunjukkan konsumen loyal karena puas mengkonsumsi kopi bubuk RANTAU di Kecamatan Argamakmur memiliki sebanyak 85\% karena rasa yang enak, aroma yang wangi, tekstur yang halus dan harga yang sesuai kualitas produk. Rata-rata nilai satisfied buyer adalah 4,03 berada pada rentang puas( 3,41-4,20). Hal ini berkaitan dengan sikap konsumen setelah mengkonsumsi kopi bubuk RANTAU menjawab puas.

\section{Habitual Buyer}

Dari gambar 8 terlihat bahwa pembeli yang loyal karena mereka sudah terbiasa mengkonsumsi kopi bubuk RANTAU sebanyak 70\%. Rata-rata habitual buyer 3,61 berada dalam kategori setuju (rentang 3,41 - 4,20) yang mengindikasikan bahwa mereka merespon setuju alasan membeli, mengkonsumsi, dan loyal karena sudah terbiasa dengan kopi bubuk RANTAU. Hal ini terkait dengan alasan konsumen mengkonsumsi kopi bubuk RANTAU karena rasa kopi yang enak.

\section{SwitcherBuyer}

Dari gambar 8 terlihat bahwa konsumen yang tidak loyal atau suka berpindahpindah membeli kopi ke merk selain kopi bubuk RANTAU sebanyak 34 persen. Rata-rata nilai switcher buyer adalah 2,71 dengan kategori cukup setuju (rentang 2,61-3,40), yang mengindikasikan bahwa pelanggan memberi tanggapan mereka berpindah membeli kopi bubuk lain selain kopi bubuk RANTAU karena dipengaruhi oleh faktor harga. Jika harga kopi merk lain lebih murah dari kopi bubuk Rantau maka mereka akan beralih membeli dan mengkonsumsi merk lain tersebut.

Pada penelitian ini, konsumen kopi bubuk RANTAU telah bisa dikatakan loyal karena nilai dari commited buyer sebesar $66 \%$ berada diatas nilai switcher buyer sebesar 34\%. Sementara, temuan dari (Yulita et al., 2014) dengan penelitian Tingkat Kepuasan dan Loyalitas Konsumen Produk Susu Cair Dalam Kemasan Koperasi Peternakan Bandung Selatan (Kpbs) di Kota Bandung" yaitu tingkat switcher buyer (65\%) >commited buyer (60\%), yang mengindikasikan konsumen dikatakan tidak loyal akan susu cair yang telah dikemas oleh KPBS di Kota Bandung. Hal ini disebabkan karena konsumen berpatokan pada harga jika harga naik maka konsumen akan pindah ke produk yang lebih murah. 


\section{Kesimpulan}

Dari hasil penelitian ini dapat ditarik kesimpulan, yaitu sikap dan perilaku konsumen dalam pengambilan keputusan mengkonsumsi kopi bubuk RANTAU karena alasan rasa yang enak dengan frekuensi mengkonsumsi produk rata-rata 3 kali sehari, jumlah pembelian terakhir rata-rata 0,25 kilo. Konsumen sudah merasakan puas terhadap produk dan berniat untuk kembali mengkonsumsi produk. Jika produk tidak tersedia dilokasi pembelian konsumen akan pergi ke tempat lain untuk membeli produk kopi bubuk RANTAU. Pengukuran kinerja atribut produk dengan IPA dari produk kopi bubuk RANTAU, harus ditingkatkan atau diperbaiki kinerja atributnya adalah tanggal kadaluarsa yang belum tercantum pada produk. Rata-rata konsumen puas terhadap usaha kopi bubuk RANTAU. Kepuasan konsumen kopi bubuk RANTAU yaitu sebesar 66\% yang menunjukkan secara keseluruhan konsumen sudah merasa puas. Konsumen kopi bubuk RANTAU sudah pada kategori loyal karena nilai nilai konsumen yang tidak loyal/suka berpindah-pindah merk kopi atau switcher buyer (34\%) lebih kecil dari nilai konsumen yang setia membeli kopi bubuk Rantau atau Commited buyer( 66\%).

\section{Daftar Pustaka}

Aini, N., Husni, S., \& Siddik, M. (2021). Analisis Perilaku Konsumen Terhadap Kopi Telapen Pada Era New Normal di Batukliang Utara Kabupaten Lombok Tengah. JURNAL AGRIMANSION, 22(2), 119-133.

AT, M. H. P. N., Situmorang, S., \& Gultom, D. T. (2020). Analisis Kepuasan dan Loyalitas Konsumen Terhadap Pisang Raja Sereh dan Pisang Cavendish di Kota Bandar Lampung. Jurnal Ilmu Ilmu Agribisnis: Journal of Agribusiness Science, 8(1), 124-131.

Diyahya, I., Sukiyono, K., \& Badrudin, R. (2016). Analisis Tingkat Kepuasan Petani Jagung Terhadap Pelayanan Lembaga Pemasarannya Di Kecamatan Lubuk Pinang Kabupaten Mukomuko. Jurnal AGRISEP: Kajian Masalah Sosial Ekonomi Pertanian Dan Agribisnis, 15(1), 45-58.

Fipiana, W. I., Lusia, V., \& Handoko, M. D. (2021). Analisis Kepuasan Pelanggan Dengan Metode Importance Performance Analysis Dalam Rangka Meningkatkan Pendapatan Di Agen Distributor Tepung Terigu Wilayah Bekasi Utara (Studi Kasus Di Agen Lestari). JURNAL MANAJEMEN FE-UB, 9(1).

Fitriani, L. N., Nurhadi, E., \& Parsudi, S. (2018). Analisis Tingkat Kepuasan dan Loyalitas Konsumen Rumah Makan Sate Ayam Ponorogo H. Turki Sobikun. Berkala Ilmiah AGRIDEVINA, 7(2), 116-130.

Lestari, N. F. I., Lestari, D. A. H., \& Suryani, A. (2020). Kepuasan, Loyalitas Konsumen dan Strategi Pengembangan Agroindustri Kerupuk Bawang di Kota Bandar Lampung. JIIA (Jurnal Ilmu-Ilmu Agribisnis), 8(3), 446-452.

Maiyanti, S. I., Irmeilyana, I., \& Verawaty, V. (2010). Aplied Customer Satisfaction Index (CSI) and Importance-Performance Analysis (IPA) to know Student Satisfaction Level of Sriwijaya University Library Services.

Marbun, D., Priyono, B. S., \& Suryanty, M. (2015). Analisis persepsi, sikap dan perilaku konsumen terhadap pancake durian (studi kasus: pancake durian produksi Celebrity Pancake). Jurnal AGRISEP Kajian Masalah Sosial Ekonomi Pertanian Dan Agribisnis, 14(2), 215-226.

Patimah, S., Priyono, B. S., \& Rasyid, W. (2016). Analisis Tingkat Kepuasan Konsumen Terhadap Usaha Benih Padi Cigeulis di Balai Benih Induk Padi dan Palawija(BBIPP) DI di Kabuapten Kepahiang, Provinsi Bengkulu. Universitas Bengkulu. 
Pranatawijaya, V. H., Widiatry, W., Priskila, R., \& Putra, P. B. A. A. (2019). Penerapan Skala Likert dan Skala Dikotomi Pada Kuesioner Online. Jurnal Sains Dan Informatika, 5(2), 128-137.

Priyono, B. S., Arianti, N. N., \& Siahaan, T. M. H. (2010). Analisis Perilaku Konsumen Produk Syngenta: Kasus di Kecamatan Ketahun Kabupaten Bengkulu Utara. Jurnal AGRISEP Kajian Masalah Sosial Ekonomi Pertanian Dan Agribisnis, 9(2), $120-129$.

Putri, V. D., Affandi, M. I., \& Nikmatullah, D. (2020). Analisis Kepuasan Konsumen dan Bauran Pemasaran Pada Agroindustri Kopi Bubuk Cap Jempol di Kota Bandar Lampung. Jurnal Ilmu Ilmu Agribisnis: Journal of Agribusiness Science, 8(1), 132-136.

Ramadhanti, E., \& Marlena, N. (2021). Analisis strategi kualitas layanan menggunakan metode importance-performance analysis (ipa). FORUM EKONOMI, 23(3), 431441.

Rasmikayati, E., Deaniera, A. N., Supyandi, D., Sukayat, Y., \& Saefudin, B. R. (2020). Analisis Perilaku Konsumen: Pola Pembelian Kopi serta Preferensi, Kepuasan dan Loyalitas Konsumen Kedai Kopi CONSUMER BEHAVIOR: PURCHASE PATTERN OF COFFEE, PREFERENCES, SATISFACTION AND LOYALTY OF COFFEE SHOP CONSUMER. Jurnal Pemikiran Masyarakat Ilmiah Berwawasan Agribisnis. Juli, 6(2), 969-984.

Riyanto, A. H., \& Riyanto, B. (2015). Analisis Peningkatan Pelayanan Stasiun Bogor Terhadap Kepuasan Pengguna Jasa Kereta Api dengan Metode Importance Performance Analysis (IPA). Jurnal Pembangunan Wilayah Dan Kota, 11(4), 391-402.

Riyanto, S., \& Hatmawan, A. A. (2020). Metode Riset Penelitian Kuantitatif Penelitian Di Bidang Manajemen, Teknik, Pendidikan Dan Eksperimen. Deepublish.

Rumondang, A., Sudirman, A., Sitorus, S., Kusuma, A. H. P., Manuhutu, M., Sudarso, A., Simarmata, J., Hasdiana, D., Tasnim, T., \& Arif, N. F. (2020). Pemasaran Digital dan Perilaku Konsumen. Yayasan Kita Menulis.

Sausan, A. (n.d.). Faktor-Faktor Yang Mempengaruhi Loyalitas Konsumen Pada Pembelian Kopi Bubuk Kapal Api di Kota Surakarta. Agrista, 9(3).

Sihombing, W. D. P., Irawan, A., \& Purwoko, A. (2019). Plasma Farmers' Satisfaction on Implementation of Nucleus-Plasma Partnership. Jurnal AGRISEP Kajian Masalah Sosial Ekonomi Pertanian Dan Agribisnis, 18(2), 371-386.

Solikatun, S., Kartono, D. T., \& Demartoto, A. (2015). Perilaku Konsumsi Kopi Sebagai Budaya Masyarakat Konsumsi (Studi Fenomenologi Pada Peminum Kopi Di Kedai Kopi Kota Semarang). Jurnal Analisa Sosiologi, 4(1).

Supriatna, I. I., \& Affandi, F. (2021). Analisis Strategi Meningkatkan Daya Saing Dengan Menggunakan Metode IPA (Importance Performance Analysis) Pada Hotel Rinjani Plaza Kota Sorong. Metode: Jurnal Teknik Industri, 4(2), 29-38.

Wutabisu, H., Indriani, S., \& Priyasmanu, T. (2021). Srtategi Segmenting, Targeting, Positioning (STP) Dalam Meningkatkan Kepuasan Konsumen Terhadap Produk Kopi Poso. Jurnal Valtech, 4(2), 217-225.

Yulita, M., Lestari, D. A. H., \& Haryono, D. (2014). Tingkat Kepuasan dan Loyalitas Konsumen Produk Susu Cair dalam Kemasan Koperasi Peternakan Bandung Selatan (KPBS) di Kota Bandung. Jurnal Ilmu Ilmu Agribisnis: Journal of Agribusiness Science, 2(2), 158-165.

Sugiyono. (2018). Metode Penelitian Kuantitatif. Bandung: Alfabeta. 